
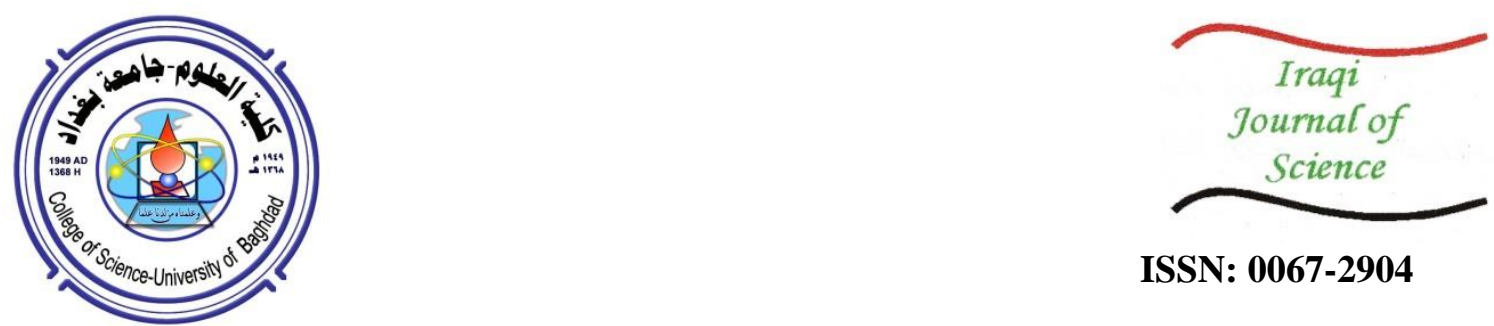

ISSN: 0067-2904

\title{
Specifications study of Hydrophobic Silica Aerogel Doped with Rhodamine 6G Prepared via Sub-Critical Drying Technique
}

\author{
Israa F. AL-Sharuee \\ Department of Physics, College of Science, Mustansiriyah University, Baghdad, Iraq.
}

Received: $26 / 8 / 2019$

Accepted: 2/6/2020

\begin{abstract}
The influence of dye laser Rhodamine 6G (R6G) on the molecular structure of silica aerogel prepared by normal drying method is reported. The study also tests the effect of dye concentration on morphological and physical properties. Fourier Transform Infrared Spectroscopy (FTIR) was used to examine this effect, in addition to Field Emission Scanning Electron Microscopy (FESEM), contact angle, and surface area measurement. It was found from FTIR data that the dye laser stays with the inner structure of samples and, at high concentration, it gives a good influence by reducing $(\mathrm{OH})$ band and increasing $(\mathrm{CH})$ band, leading to changing the contact angle from $\left(123^{\circ}\right)$ to $\left(145^{\circ}\right)$. Whereas particle size varied from $22 \mathrm{~nm}$ to $47 \mathrm{~nm}$ after doping, resulting in a decrease in surface area from $673 \mathrm{~m}^{2} / \mathrm{gm}$ before doping to 357 $\mathrm{m}^{2} / \mathrm{gm}$ after doping. It was also found that the samples became lightweighted through the noticeable decrease in the amount of density from 0.28 to $0.17 \mathrm{gm} / \mathrm{cm}^{3}$.
\end{abstract}

Keywords: Molecular structure, sub-critical drying, silica aerogel, Rhodamine 6G, FTIR.

والمحضرة بتقنية التجفيف دون الحرجة6Gمواصفات السيليكا ايروجل المطعمة بالرودامين

$$
\begin{aligned}
& \text { اسراء فاخر خلف الشرع } \\
& \text { قسم الفيزياء ، كلية العلوم ، الجامعة الستتصرية ، بغداد، العراق } \\
& \text { الخلاصة } \\
& \text { تم البحث عن تأثير الصبغة الليزرية رودامين (6G) على البنية الجزيئية لهلام السليكا التي تم تحضيرها } \\
& \text { بطريقة التجفيف العادية ، كما تضمنت الدراسة تأثير تركيز الصبغة على الخصائص المائين المورفولوجية والفيزيزيائية. }
\end{aligned}
$$

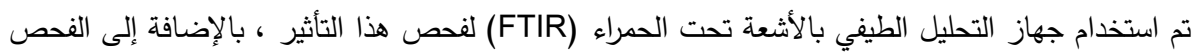

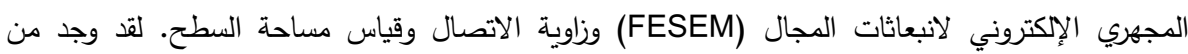

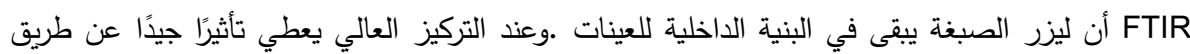

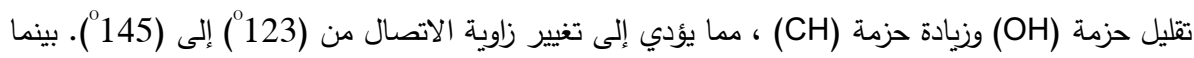

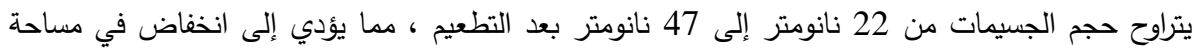

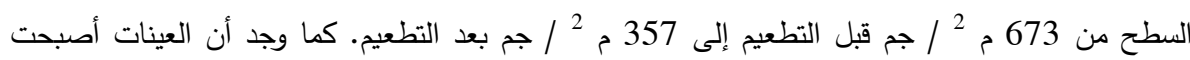

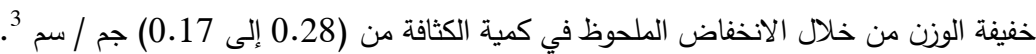

\section{Introduction}

In general, aerogels indicate dry gels with a very high virtual or specific pore volume, high surface area, low electricity, and high specific transparency [1,2]. However, the value of these physical 
characteristics is provisional on the nature of the solid, while no official convention truly exists [3]. By considering latest improvements in the creation of aerogels, it is certainly more representative to describe these materials with reference to the original indication of Kastler, simply as gels in which the liquid has been substituted by air, with very reasonable shrinkage of the immobile network $[4,5]$. The chemical structures of the materials that were prepared as aerogels have become more and more numerous. Firstly, these chemical mixtures, termed precursors, are the essential materials, since that the oxide gel was made from metallic salts [6,7]. Recently, silica aerogels have gained a greater extent of interest due to their outstanding properties and their current and prospective uses in a wide variety of technological areas $[8,9]$. Aerogel made from silica is a material with nanostructure property, high exact surface area, high porosity, low dielectric constant, small density, and excellent heat insulation properties $[10,11]$. The important step in the production of silica aerogel is the elimination of the pore of liquid without collapsing the three dimensional structure [12]. The networks of silica are either hydrophilic or hydrophobic, depending on the environments or conditions of preparation. Supercritical drying is one of the techniques used to prepare aerogel with a high surface area and porosity. However the high cost and risk of this method led to adopting normal drying method as a replacement [13]. During normal drying, the evaporation of liquid from moist gel produces a capillary tension (because of a liquid-vapor interface), and this strain is balanced through the compressive force on the solid monolithic, which gives rise to shrinkage of the gel [5, 14]. The modification of the surface by exchanging solvents from the wet gel is very necessary to inhibit any type of capillary tension and shrinkage throughout drying $[15,16]$. The wet gel must be aged in a saline solution to increase its strength and stiffness. Finally, pore liquid must be substituted by low surface tension solvent to decrease related drying shrinkage and capillary stress [17]. The doping of aerogel has been utilized successfully in several reactions of catalytic oxidation. Strong impacts were recorded on the physical and chemical properties, such as account density, percentage of shrinkage, contact angle, thermal conductivity, and the optical transparency [17]. In general, the particles of these metals are found to be trapped in the host of silica monolith in a very small quantity, without any bonding with silica network, which was confirmed by many researchers. Some researchers found the ability to use aerogel doped in dye laser as a gain media in some types of this dye lasers [18]. Others succeeded to prepare silica aerogel doped in Coumarin dye. They observed that the compatibility of this dyes with silica gel gives a good homogeneity and transparency [19]. Whereas one research studied the effect of Alumina nanoparticles prepared by using the sol-gel method on photoluminescence (fluorescence and absorption) of Rhodamine 110 dye laser solution [20]. In this work, hydrophobic aerogel prepared with excellent specifications in terms of low density, shrinkage-free, and high surface area, was synthesized via normal drying method; Rhodamine 6G was dissolved in ethanol for doping, using tetraethylorthosilicate (TEOS) as a precursor and trimethylchlorosilan (TMCS) and n-hexane for surface modification.

\section{Materials}

Tetraethylorthosilicate (TEOS, $99 \%$ ) Trimethylchlorosilan (TMCS, > (99\%), and n-Hexane (> 98 $\%)$ were equipped from Sigma Aldrich. Rhodamine $6 \mathrm{G}$ chmical formula $\left(\mathrm{C}_{28} \mathrm{H}_{31} \mathrm{~N}_{2} \mathrm{O}_{3} \mathrm{Cl}\right)$, molecular weight $(479.02(\mathrm{~g} / \mathrm{mol}))$ and purity $(96 \%)$ Fluka, ethanol $>(99 \%)$, hydrochloric acid chmical formula $(\mathrm{HCl})$, purity > $(99.0 \%)$ Qualigens Fine Chemicals, Ammonia solution chmical formula $\left(\mathrm{NH}_{3},\right)$ provided from Merck, India), Ammonium Fluoride $\left(\mathrm{NH}_{4} \mathrm{~F}\right)$ from Loba Chemie.

\subsection{Samples preparation and characterization methods}

Hydrophobic aerogel samples of silica gel were prepared via two-step acid-base catalysis procedure, as in the following steps. TEOS was mixed with ethanol: water: and hydrochloric acid (molar ratios 2.16: 5.5: 0.24, respectively). The $\mathrm{pH}$ for the final mixture was fixed at 8 . The lowest gel time, higher transparency, and fewer cracks facilitate the examination and measurements required by this research. The sol was subjected to magnetic stirring at $303{ }^{\circ} \mathrm{K}$ for $30 \mathrm{~min}$. After the hydrolysis of the solution for $48 \mathrm{hr}$ (for more aging), the dye was added with varied amounts according to the required concentration. The last step of preparation was the addition of $\mathrm{NH}_{4} \mathrm{OH}: \mathrm{NH}_{4} \mathrm{~F}$ with the ratio of 1:0.5 as a catalyst. The produced sol was transformed to wet gel in tubes $(3.3 \mathrm{~cm}$ diameter) made from plastic (to prevent sticking), and then aged at room temperature. To separate any unreacted monomer from the wet gel network, these gels were washed with ethanol for five times each day, using ethanol for each sequential step. The washed wet gel was modified by soaking in TMCS-Hexane)mixture (6 wt. \% TMCS in hexane) for three times within $72 \mathrm{hr}$, which was found to be the best modification time 
after many examinations. The process was performed under $60^{\circ} \mathrm{c}$ followed by drying at room temperature. The effects of doping on structural and physical properties were determined by using FTIR technique. The chemical bonding of the silica aerogel microspheres were examined in the range of $400-4000 \mathrm{~cm}^{-1}$ using $\mathrm{KBr}$ pellets, which allow transmission of IR radiation in the range 370 to $10000 \mathrm{~cm}^{-1}$, as needed in this work'. The phases of doping of nano silicate were determined by using XRD. Microstructural studies of the aerogel samples were accomplished using FESEM. To estimate the degree of hydrophobicity, the contact angle $(\theta)$ of a water droplet placed on the surface of the aerogel was measured using a contact angle meter [21].

\section{Results and discussion}

\subsection{FTIR synthesis}

The effects of doping in R6G and the variation of concentration on structural properties of hydrophobic silica aerogel are illustrated in Figure-1. The characteristic vibration frequencies measured through FTIR spectra for the modified surface and intensities of the $\mathrm{O}-\mathrm{H}, \mathrm{C}-\mathrm{H}, \mathrm{Si}-\mathrm{C}$ and $\mathrm{Si}$ O-Si bands for the samples are shown in Tables-(1 and 2).

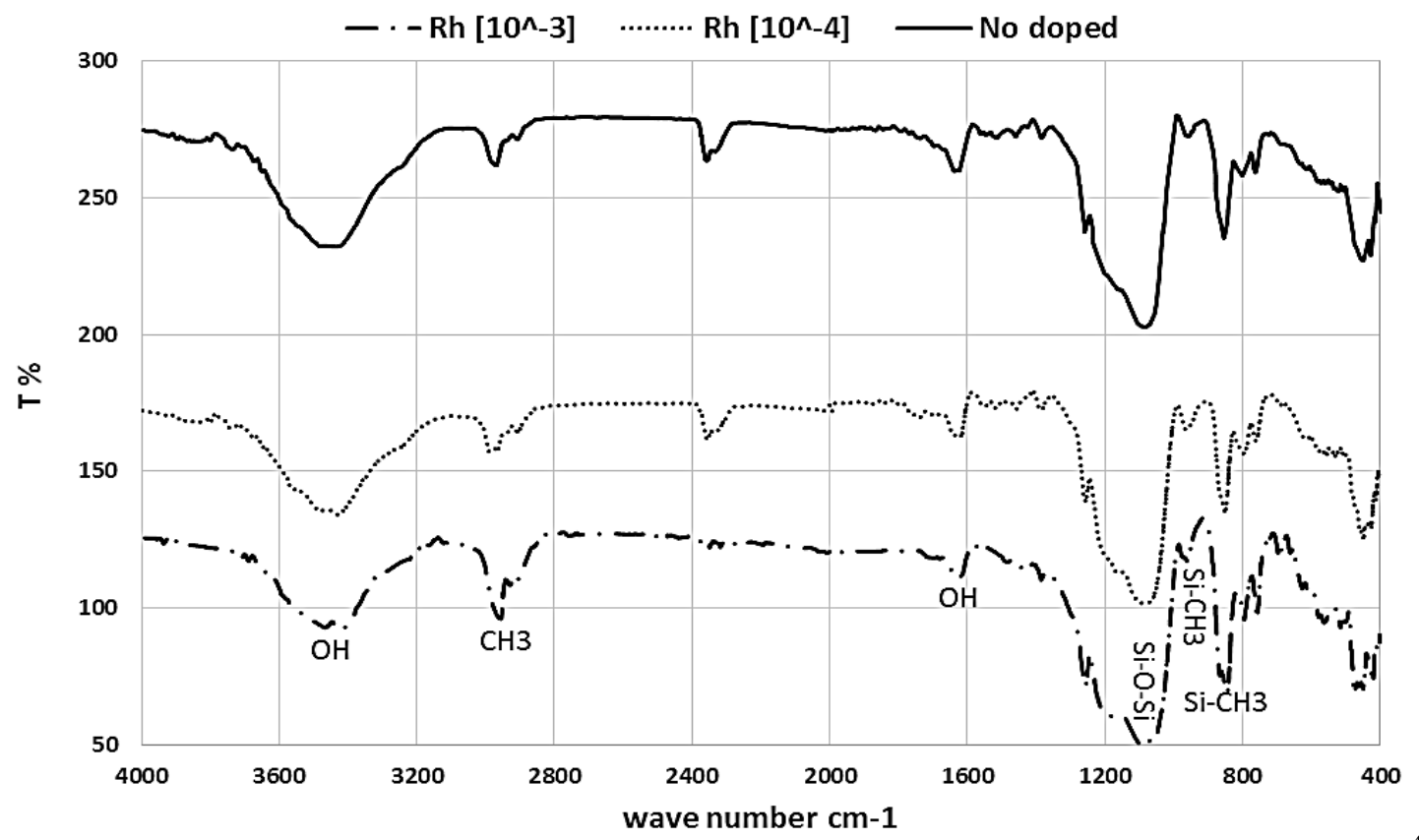

Figure1-FTIR spectra for the modified surface of doped and non-doped aerogel in R6G with $10^{-4}$ and $10^{-3} \mathrm{gm} / \mathrm{cm}^{-3}$.

Table 1-Intensity values of $\mathrm{O}-\mathrm{H}, \mathrm{C}-\mathrm{H}, \mathrm{Si}-\mathrm{C}$ and $\mathrm{Si}-\mathrm{O}-\mathrm{Si}$ bands for doped and non-doped aerogel in R6G with $10^{-4}$ and $10^{-3} \mathrm{gm} / \mathrm{cm}^{-3)}$, where max= higher value.

\begin{tabular}{c|c|c|c|c|c|c} 
& $\boldsymbol{S i - C}$ & $\boldsymbol{S i - O - S i}$ & $\boldsymbol{C}-\boldsymbol{H}$ & $\boldsymbol{C}-\boldsymbol{H}$ & $\boldsymbol{O}-\boldsymbol{H}$ & $\max$ \\
\hline $\begin{array}{c}\text { without } \\
\text { doping }\end{array}$ & 38.136 & 2.176 & 33.517 & 61.613 & 21.071 & 78 \\
\hline $\boldsymbol{R}\left[\mathbf{1 0}^{-4}\right]$ & 46.28 & 3.62 & 39.13 & 65.63 & 42.15 & 78.9467 \\
\hline $\boldsymbol{R}\left[\mathbf{1 0}^{-3}\right]$ & 53.41 & 9.44 & 26.85 & 69.94 & 42.62 & 85.9218
\end{tabular}

Table 2- Characteristic vibration frequencies measured through FTIR spectra for the modified surface of doped and non-doped aerogel in R6G with $10^{-4}$ and $10^{-3} \mathrm{gm} / \mathrm{cm}^{-3}$.

\begin{tabular}{c|c|c|c|c|c} 
& length & OH\% & CH\% & $\boldsymbol{C H 2 \%}$ & SI-C\% \\
\hline $\begin{array}{l}\text { without } \\
\text { doping }\end{array}$ & 74.824 & 75.08045 & 21.61189 & 58.66612 & 52.57438 \\
\hline $\boldsymbol{R}\left[10^{-4}\right]$ & 80.1782 & 80.5633 & 36.89557 & 84.91485 & 59.76462 \\
\hline $\boldsymbol{R}\left[\mathbf{1 0}^{-3}\right]$ & 75.3267 & 48.84948 & 17.67859 & 52.85868 & 43.36669
\end{tabular}


It is clear that both spectra are demonstrated at an $\mathrm{O}-\mathrm{H}$ stretching region peaking at $3450 \mathrm{~cm}^{-1}$, where some freely vibrating and a majority of hydrogen-bonded $\mathrm{OH}$ groups are apparent. In addition, there is a weak peak that lies near $1610 \mathrm{~cm}^{-1}$ and attributed to the $\mathrm{OH}$ group. This peak becomes weaker when increasing dye concentration. It is observed that these results are caused by the ethanol residue, indicating that very low amount of molecular water remained in the gel at this stage. The spectra also displayed small residual features near $2967 \mathrm{~cm}^{-1}$ due to organic residues. Both gel spectra exhibited bands centred near $950-960 \mathrm{~cm}^{-1}$ which are absent in the thermal oxide. The peaks of higher frequency may be attributed to stretching vibrations of $\mathrm{Si}-\mathrm{OH}$ or $\mathrm{Si}-\mathrm{O}-\mathrm{Si}$ groups, which is in agreement with previous results [22], whereas the peak of lower frequency may hesitantly be related with vibrating motions of the same species. In this region, the doping in the dye laser caused effects of increase or decrease to this peak. In addition, there was a lower frequency band at $452 \mathrm{~cm}^{-1}$, as a result of vibration motions of the oxygen atoms columnar to the $\mathrm{Si}-\mathrm{O}-\mathrm{Si}$ bands, attended by some $\mathrm{Si}$ reference. The frequency between bands close to $800 \mathrm{~cm}^{-1}$ is attributed to the symmetric stretching location of the Si-O-Si spanning angle $(\theta)$. The high-frequency dominant band near $1091 \mathrm{~cm}^{-1}$ is a result of antisymmetric stretching of the oxygen atoms alongside a direction equivalent to $\mathrm{Si}-\mathrm{O}-\mathrm{Si}$, this bond is impact on the ratio of TEOS in mixing. In addition, there is a weak absorption at region 523 $\mathrm{nm}$ (in the case of high doping), which is attributed to R6G. At low concentration, No changing be observed in the samples propertiese.

\subsection{Morphological analysis}

The morphological features of the aerogel samples with and without doping in $10^{-4}$ and $10^{-3} \mathrm{gm} / \mathrm{cm}$ of R6G were described by using FESEM with different magnifications. As shown in Figures-(2a, b and $\mathrm{c}$ ), there were characteristic tridimensional disordered porous structures, aggregated and sphereshaped particles with diameters of about 22-47 $\mathrm{nm}$. The porous construction was conserved after the alcohothermal reduction, whereas the aggregation of the nanoparticles was observed

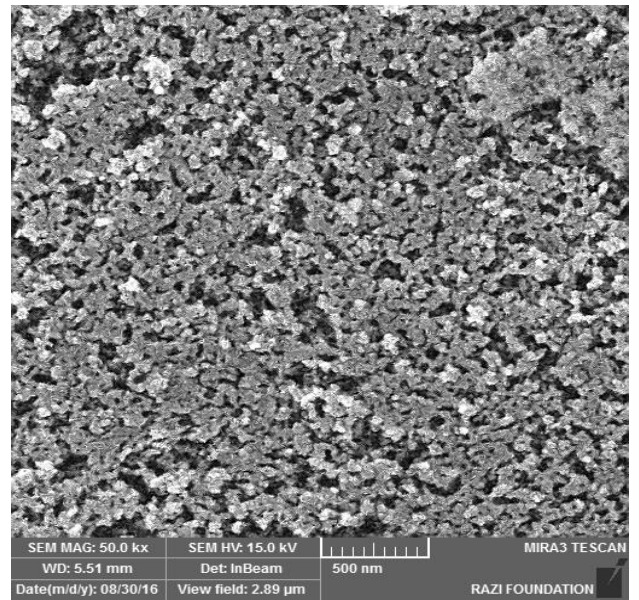

(a)

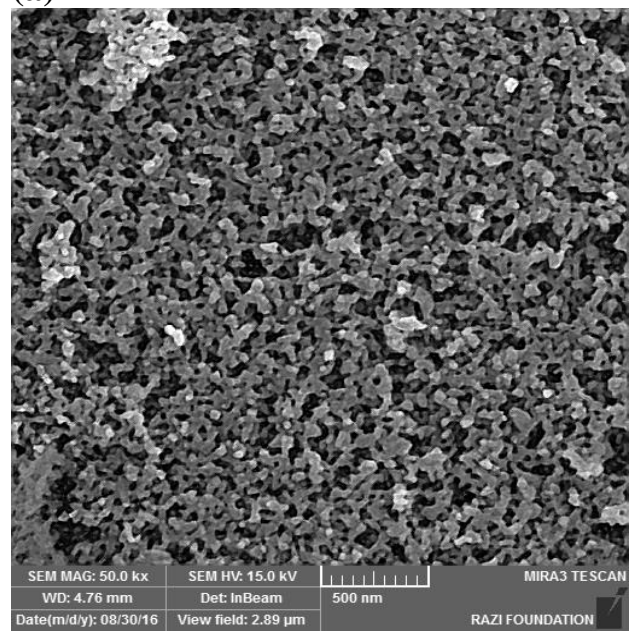

(b)
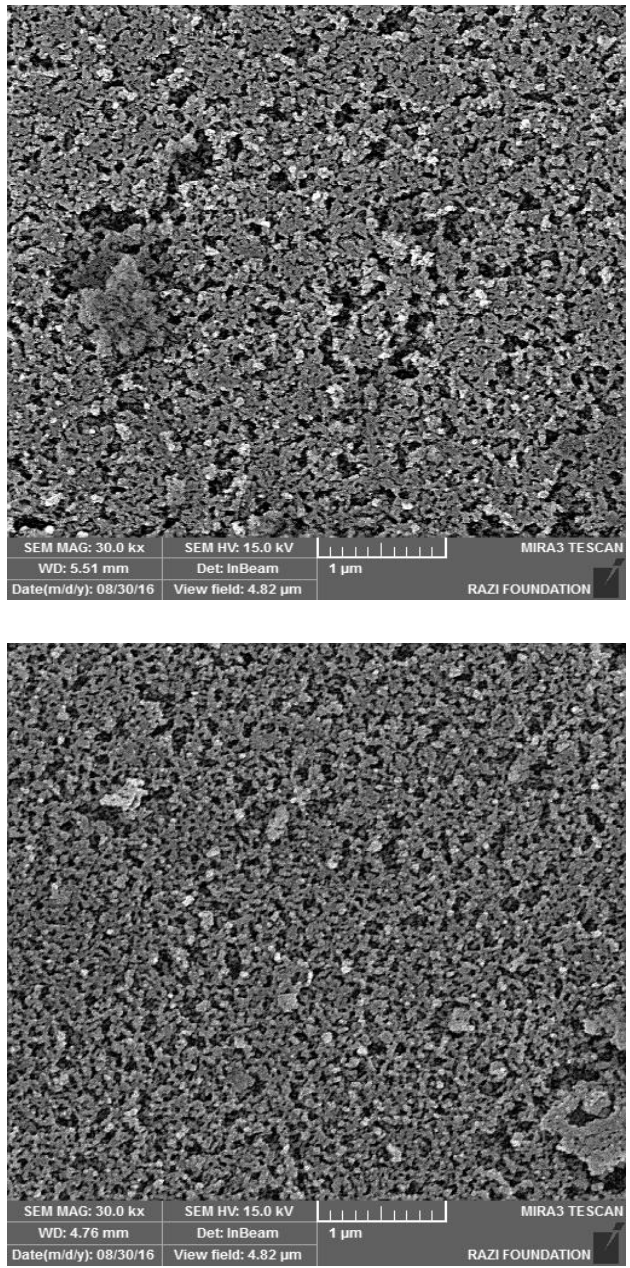

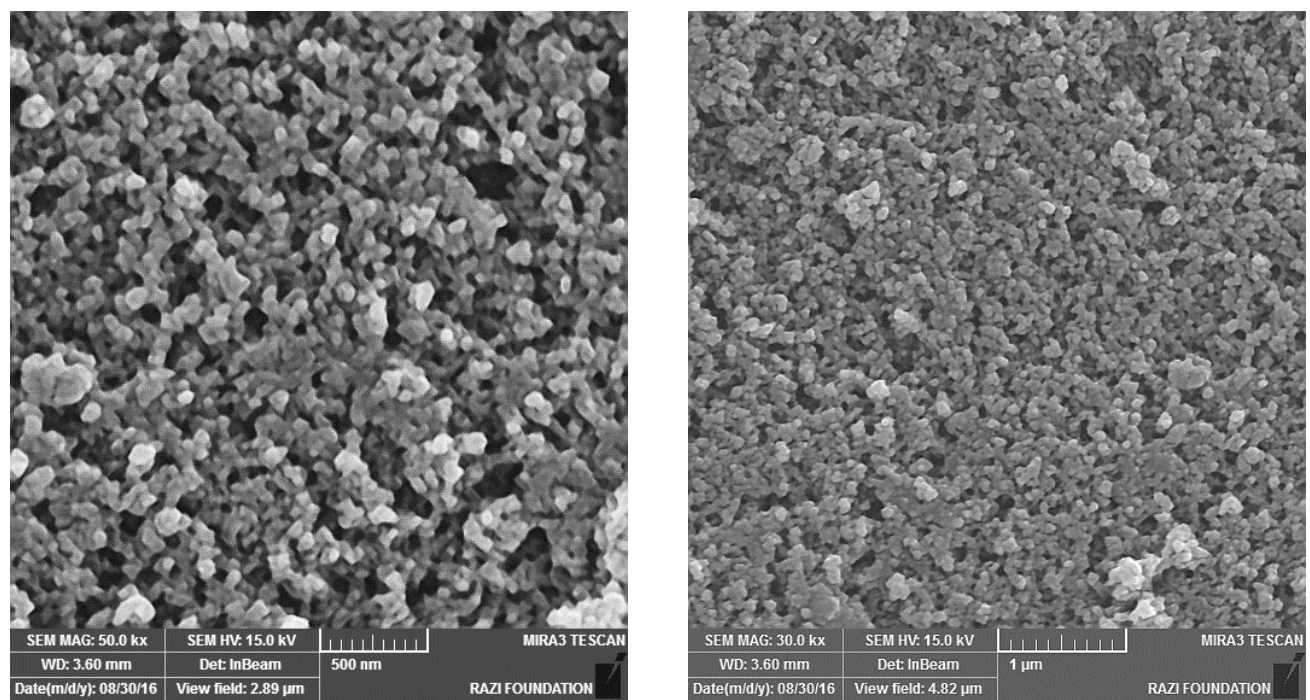

(c)

Figure 2-FESEM images of silica aerogel before and after doping with R6G. (a)Without doping (b) doping with $10^{-4} \mathrm{mg} / \mathrm{cm}^{-3}$, and (c) doping with $10^{-3} \mathrm{mg} / \mathrm{cm}^{-3}$.

\subsection{Contact angle measurement}

The determination of hydrophobicity without and with doping was performed by measuring the contact angle. Figure- 3 a, b, and c illustrates the image of samples of aerogel without and with doping with concentrations of $10^{-4}$ and $10^{-3} \mathrm{gm} / \mathrm{cm}^{3}$, respectively. The effects of doping on the dye laser are very clear through the observed increase of the contact angle with increasing the ratio of doping. This effect is possibly because of the existence of $\mathrm{Cl}$ in dye structure and the ability of the molecular dye to connect with $-\mathrm{OH}$, leading to not allowing $\mathrm{H}$ for attaching with $-\mathrm{OH}$, which causes the humidity of the aerogel. It can be stated that the dye laser makes surface modifications, producing hydrophobic aerogel with high contact angle.

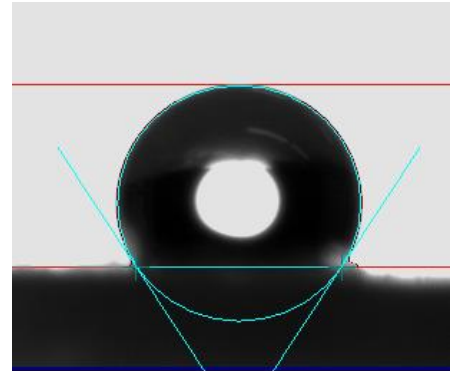

without

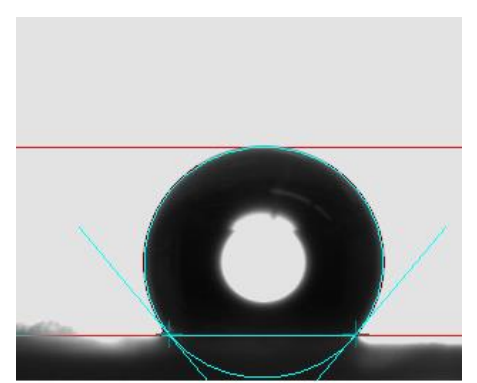

$10^{-4} \mathrm{mg} / \mathrm{cm}^{-3}$

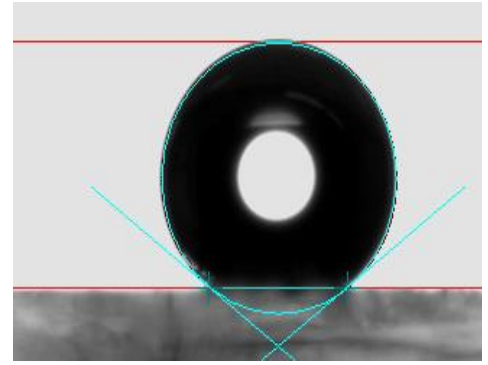

$10^{-3} \mathrm{mg} / \mathrm{cm}^{-3}$

Figure 3-Contact angle measurements of the prepared doped silica aerogels without and with $10^{-}$ ${ }^{4} \mathrm{mg} / \mathrm{cm}^{-3}$ and $10^{-3} \mathrm{mg} / \mathrm{cm}^{-3}$ of R6G.

Table 3-Some of the physical properties for the modified surface of doped and non-doped silica aerogel in R6G with $10^{-4}$ and $10^{-3} \mathrm{gm} / \mathrm{cm}^{-3}$.

\begin{tabular}{|c|c|c|c|}
\hline 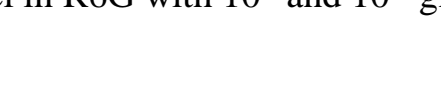 & Without doping & $\begin{array}{c}\text { Doping with } 10^{-} \\
{ }_{4}^{4} \mathrm{mg} / \mathrm{cm}^{-3}\end{array}$ & $\begin{array}{l}\text { Doping with } \\
10^{-3} \mathrm{mg} \mathrm{cm}^{-3}\end{array}$ \\
\hline Surface area $\left(\mathrm{m}^{2} / \mathrm{gm}.\right)$ & 673 & 458 & 357 \\
\hline Average Particle size (nm) & 22 & 31 & 47 \\
\hline Contact angle $\theta$ & 123.85 & 130.05 & 145.48 \\
\hline \%of shrinkage & 66.61 & 52.83 & 42.39 \\
\hline $\operatorname{Density}\left(\mathrm{gm} . / \mathrm{cm}^{3}\right)$ & 0.28 & 0.20 & 0.17 \\
\hline
\end{tabular}


Doping in R6G affected some properties of samples by increasing the contact angle and average particle size, leading to a decrease in the surface area. While it was noticed that the density of samples was decreased with a further decrease in the percentage of shrinkage. From these results, it can be stated that doping in R6G enhances the physical and structural properties of hydrophobic silica aerogel.

\section{Conclusions}

Aerogel samples prepared via normal drying and doping with dye laser R6G were influenced in some of their physical and structural properties by the remaining of the dye within their structures and keeping its position inside the samples. In addition, this doping added more modifications on the surface by increasing the contact angle, leading to an increase in the hydrophobicity property. This effect is due to the existence of $\mathrm{Cl}$ in dye structure and the ability of the molecular dye to connect with $-\mathrm{OH}$, leading to preventing $\mathrm{H}$ rom attaching with $-\mathrm{OH}$, which causes the humidity of the aerogel. In addition, the doping conferred more homogenous structure and virtually lightweighted material.

Results of this work indicated the possibility of obtaining doped silica aerogel with R6G in different concentration and have advantages compared with samples without doping.

\section{ACKNOWLEDGEMENTS}

The author acknowledges to Baghdad University and Ibn Sina Center of science to facilitate and support the testing of some samples for this work.

\section{REFERENCES}

1. Yun, S., Luo, H. and Gao, Y. 2014. "Superhydrophobic silica aerogel microspheres from methyltrimethoxysilane: rapid synthesis via ambient pressure drying and excellent absorption properties," RSC Advances, 4: 4535-4542.

2. Zhang, D., Yu, W., Hao, D., Li, L., Liu, H. and Lu, Z. 2012. "Functional nanostructured surfaces in hybrid sol-gel glass in large area for antireflective and super-hydrophobic purposes," Journal of Materials Chemistry, 22: 17328-17331.

3. Hashem, D.F., Foxton, R., Manoharan, A., Watson, T.E. and Banerjee, A. 2014. "The physical characteristics of resin composite-calcium silicate interface as part of a layered/laminate adhesive restoration," Dental Materials, 30: 343-349.

4. Alemán, J., Chadwick, A.V., He, J., Hess, M., Horie, K., Jones, R.G. et al. 2007. "Definitions of terms relating to the structure and processing of sols, gels, networks, and inorganic-organic hybrid materials (IUPAC Recommendations 2007)," Pure and Applied Chemistry, 79: 1801-1829.

5. Rao, A.V. Rao, A.P. and Kulkarni, M. 2004. V"Influence of gel aging and $\mathrm{Na} 2 \mathrm{SiO}$ 3/H $2 \mathrm{O}$ molar ratio on monolithicity and physical properties of water-glass-based aerogels dried at atmospheric pressure," Journal of non-crystalline solids, 350: 224-229.

6. Aegerter, M.A., Leventis, N. and Koebel, M. 2011. "Advances in sol-gel derived materials and technologies," ed: Springer.

7. Yaseen, Z.A. and Yiseen, G.A. 2019. "The influence of anodization time with the electrochemical cell design on the fabrication process of porous silicon nanostructures," Iraqi Journal of Science, 60: $937-942$.

8. Patel, R.P., Purohit, N.S. and Suthar, A.M. 2009. "An overview of silica aerogels," International Journal of ChemTech Research, 1: 1052-1057.

9. Smirnova, I., Suttiruengwong, S., Seiler, M. and Arlt, W. 2005. "Dissolution rate enhancement by adsorption of poorly soluble drugs on hydrophilic silica aerogels," Pharmaceutical development and technology, 9: 443-452.

10. Hu, W., Li, M., Chen, W., Zhang, N., Li, B., Wang, M. et al. 2016. "Preparation of hydrophobic silica aerogel with kaolin dried at ambient pressure," Colloids and Surfaces A: Physicochemical and Engineering Aspects, 501: 83-91, 2016.

11. Mahadik, D., Lee, Y.K., Chavan, N., Mahadik, S. and Park, H.H. 2016. "Monolithic and shrinkage-free hydrophobic silica aerogels via new rapid supercritical extraction process," The Journal of Supercritical Fluids, 107: 84-91.

12. García-González, C. and Smirnova, I. 2013. "Use of supercritical fluid technology for the production of tailor-made aerogel particles for delivery systems," The Journal of Supercritical Fluids, 79: 152-158. 
13. Ivanov, P., Hristov, Y., Bogdanov, B. and Pashev, P. 2014. "Synthesis of silica aerogel by surface modification," Nauch. Trudy Rusensk. Univer, 53.

14. Hameed, T. and Kadhem, S. 2019. "Plasma diagnostic of gliding arc discharge at atmospheric pressure," Iraqi Journal of Science, 60: 2649-2655.

15. Al-sharuee and , I.F. and Mohammed, F.H. 2019. "Investigation study the ability of superhydrophobic silica to adsorb the Iraqi crude oil leaked in water," in IOP Conference Series: Materials Science and Engineering, 2019, p. 012116.

16. Al-sharuee, I.F. 2019. "Thermal Conductivity Performance of Silica Aerogel after Exposition on Different Heating under Ambient Pressure," Baghdad Science Journal, 16: 0770-0770.

17. Nayak, J. and Bera, J. 2009. "Preparation of silica aerogel by ambient pressure drying process using rice husk ash as raw material," Transactions of the Indian Ceramic Society, 68: 91-94.

18. Costela, A., García Moreno, I., Gomez, C.,Garcia, O., Sastre, R., Roig, A. et al., 2005. "Polymerfilled nanoporous silica aerogels as hosts for highly stable solid-state dye lasers," The Journal of Physical Chemistry B, 109: 4475-4480, 2005.

19. Haque, F.Z. and Husain, M. 2014. "Synthesis and spectroscopic characterization of coumarin 440 dye doped silica gel rods," Optik-International Journal for Light and Electron Optics, 125: 23082312.

20. Mohamed, A.N. 2017. "Effect of Alumina Nanoparticles on the Photoluminescence of Rh110 Laser Dye Doped with organically modified silicate (ORMOSIL)," MJPS, 4, 2017.

21. Rao, A.P., Rao, A.V. and Pajonk, G. 2007. "Hydrophobic and physical properties of the ambient pressure dried silica aerogels with sodium silicate precursor using various surface modification agents," Applied surface science, 253: 6032-6040.

22. Li, L., Li, B. and Zhang, J. 2016. "Dopamine-mediated fabrication of ultralight graphene aerogels with low volume shrinkage," Journal of Materials Chemistry A, 4: 512-518. 